Article

\title{
Moisture Estimation in Cabinet Dryers with Thin-Layer Relationships Using a Genetic Algorithm and Neural Network
}

\author{
Behzad Maleki ${ }^{1}$, Mahyar Ghazvini ${ }^{2}$, Mohammad Hossein Ahmadi ${ }^{3}$, Heydar Maddah ${ }^{4}$ and \\ Shahaboddin Shamshirband $5,6, *$ (D) \\ 1 Energy Institute of Higher Education, Saveh 39177-67746, Iran; behzadgmaleki@gmail.com \\ 2 Department of Renewable Energy and Environmental Engineering, University of Tehran, Tehran 1417466191, \\ Iran; m.ghazvini@ut.ac.ir \\ 3 Faculty of Mechanical Engineering, Shahrood University of Technology, Shahrood 3616713455, Iran; \\ mohammadhosein.ahmadi@gmail.com \\ 4 Department of Chemistry, Payame Noor University (PNU), P.O. Box, Tehran 19395-3697, Iran; \\ heydar.maddah@gmail.com \\ 5 Department for Management of Science and Technology Development, Ton Duc Thang University, \\ Ho Chi Minh City, Vietnam \\ 6 Faculty of Information Technology, Ton Duc Thang University, Ho Chi Minh City, Vietnam \\ * Correspondence: shahaboddin.shamshirband@tdtu.edu.vn
}

Received: 21 June 2019; Accepted: 25 July 2019; Published: 3 November 2019

\begin{abstract}
Nowadays, industrial dryers are used instead of traditional methods for drying. When designing dryers suitable for controlling the process of drying and reaching a high-quality product, it is necessary to predict the gradual moisture loss during drying. Few studies have been conducted to compare thin-layer models and artificial neural network models on the kinetics of pistachio drying in a cabinet dryer. For this purpose, ten mathematical-experimental models with a neural network model based on the kinetic data of pistachio drying were studied. The data obtained was from a cabinet dryer evaluated at four temperatures of inlet air and different air velocities. The pistachio seeds were placed in a thin layer on an aluminum sheet on a drying tray and weighed by a scale attached to the computer at different times. In the neural network, data was divided into three parts: Educational (60\%), validation (20\%) and testing (20\%). Finally, the best mathematical-experimental model using a genetic algorithm and the best neural network structure for predicting instantaneous moisture were selected based on the least squared error and the highest correlation coefficient.
\end{abstract}

Keywords: cabinet dryer; genetic algorithm; neural network; temperature; air velocity; moisture

\section{Introduction}

During the past few years, some studies have focused on applying neural network models for different engineering applications [1,2]. As an example, Baghban et al. [3] used an artificial neural network (ANN) approach for predicting the heat transfer of coiled tube heat exchanger. Additionally, pulsating heat pipes' thermal resistance has been estimated by Ahmadi et al. [4] with the help of an ANN. In addition to these, some investigations have been done on evaluating the thermal performance of various applications with the help of neural networks [5-8]. Among these applications, artificial neural networks have been widely used in drying processes and other processes [9-16]. Farkas [17] focused on ANN modeling of heat and mass transfer in drying technology. As mentioned in the results, neural networks can be properly utilized in order to detect the moisture distribution in a fixed-bed 
dryer. Also, a hybrid neuro-fuzzy model named ANFIS has been utilized by Jumah et al. [18] for the aim of modeling intermittent drying of grains. Furthermore, Koni et al. [19] proposed a controller based on the ANFIS model for baker's yeast drying. The efficiency of the introduced ANFIS was identified by using that controller.

On the other hand, limited investigations have been carried out regarding pistachio drying. In 2008, Mohammadpour et al. [20] examined pistachio drying in a fluid bed dryer. They concluded that changes in moisture content over time are strongly influenced by the temperature and speed of the air. They also stated that the effect of temperature on kinetic drying is higher than the air velocity. The researchers also used thin-layer models to predict pistachio drying data and concluded that the binary model, in all conditions, and the Henderson and Pabis model at higher temperatures, and velocities would be the best predictors of experimental data. Zang et al. [21] used the neural network for the prediction of the final moisture content of the product, the drying rate, and the energy consumption indices in the process of drying. The input vector consisted of the four parameters of layer thickness, hot air flow, drying air temperature and drying time. Islam et al. [22] predicted the rate of drying of thin potatoes in dryers by a neural network. The purpose of this study was to develop a neural network model for drying thin-potato plates under conditions of different speeds of hot air, different temperatures, and moisture content, in a one-dimensional liquid diffusion model.

The liquid diffusion model has been used to produce data for different thicknesses of thin potato plates under different conditions of air velocity, temperature, and moisture. Data were used to predict the rapid drying rate in the neural network. The proposed model of the neural network had the proper accuracy in determining the rate of drying in the range of the studied parameters. Arenturk et al. [23] compared the genetic algorithm and neural network in the process of drying thin carrots.

The carrots at different temperatures and velocities, and three thicknesses (5.7, 5 and $10 \mathrm{~mm}$ ) were dried in a thin layer. Then, the data were called in the neural network. In this research, carrot, thin-layer drying was investigated on an experimental scale, and a comparison between regression analysis and ANN was conducted in the process of dynamic drying of carrot layers. Among the four mathematical models of drying, the best model for estimating carrot dryness was the surface response method. Then, this model was compared with the ANN. It was observed that the ANN was more than $0.05 \%$ more effective than the modified version of the model, and the neural network model has been proven to be very successful when predicting the dynamics of drying systems.

In addition, Zbysinsky et al. [3] worked on an investigation for modeling the moisture evaporation process in a fluid bed dryer with the help of ANN. Also, Zubisinsky et al. [24] to predict the heat transfer coefficient of various materials; Mittal and Zang [25] to estimate moisture and temperature in thermal processes; Brüyart et al. [26] to model the heat and mass transfer phenomenon, and to study the process of qualitative changes in biscuit processing; Hernandez et al. [27] for estimating heat and mass transfer in the process of drying starch and mango; and Poonnoy et al. [28,29] to model the prediction of the moisture content of the fungus, and predict the temperature and moisture content of the thin layer of tomato in the microwave-vacuum dryer used the neural network (ANN). All of the above studies show the effectiveness of thin-layer models, as well as the neural network model for determining the kinetics of drying agricultural products. Few studies have been conducted to compare the thin-layer models and artificial neural network models on the kinetics of pistachio drying in a cabinet dryer. For that purpose, ten mathematical-experimental models with a neural network model based on the kinetic data of pistachio drying were studied.

\section{Study Procedure}

Thin layer models were used to predict the instantaneous moisture content. Calculation of coefficients and a computer simulation of pistachio drying were used to optimize and control the relevant drying systems. In this research, the data were obtained from an experimental cabinet dryer at temperatures of $50{ }^{\circ} \mathrm{C}, 55^{\circ} \mathrm{C}$, and $60^{\circ} \mathrm{C}$, and air velocity of $0.75 \mathrm{~m} / \mathrm{s}$ and $1.25 \mathrm{~m} / \mathrm{s}$. Before the 
experiment, the moisture content of pistachios was measured in the range of 37-36\% (based on wet weight). During the drying process, the moisture dropped from $37 \%$ to $5 \%$.

\section{Designing an Artificial Neural Network to Predict Instantaneous Moisture}

The purpose of this section is to predict the moisture content of pistachios during drying by taking into account three input parameters - the velocity of hot air temperature, temperature, and time, all using artificial neural networks. Hence, the multi-layer perceptron (MLP) networks with the learning algorithms of Leungberg-Marguerite were used to train the network. A neural network was designed with three input neurons (temperature, air velocity, and time) and a neuron output layer (moisture content). In this research, Matlab 7.12 software was used. Also, to increase the accuracy and speed of convergence, the artificial neural network, input and output data including inlet air temperature $\left(T_{i}\right)$, contact time $\left(t_{i}\right)$, inlet air velocity $\left(v_{i}\right)$ and moisture content $(M)$ were calculated in the form of a dimensionless unit in the range of $(0-1)$.

$$
\begin{gathered}
M_{R}=\frac{M-M_{e}}{M_{o}-M_{e}} \\
T_{n}=\frac{T_{i}-T_{\min }}{T_{\max }-T_{\min }} \\
t_{n}=\frac{t_{i}-t_{\min }}{t_{\max }-t_{\min }} \\
v_{n}=\frac{v_{i}-v_{\min }}{v_{\max }-v_{\min }}
\end{gathered}
$$

$M_{e}$ and $M_{i}$ express the final moisture content and the initial moisture content, respectively. $T_{n}, t_{n}$ and $v_{n}$ indicate the temperature, time, and the inlet air velocity in the dimensionless form.

\section{Calculating the Coefficients of the Thin Layer Drying Equations}

Table 1 presents the semi-experimental thin-layer drying equations. In each of the following forms, a prevalent thin layer model was examined.

Table 1. Sub-equations of thin layer drying [30].

\begin{tabular}{lll}
\hline \multicolumn{1}{c}{ Name } & \multicolumn{1}{c}{ Thin-Layer Drying Models } & \multicolumn{1}{c}{ Model Equation } \\
\hline Newton & $\mathrm{MR}=\exp (-\mathrm{kt})$ & \multicolumn{1}{c}{ References } \\
Page & $\mathrm{MR}=\exp \left(-\mathrm{kt} \mathrm{n}^{\mathrm{n}}\right)$ & O'callaghanetal (1971), [31] \\
Henderson and Pabis & $\mathrm{MR}=\mathrm{aexp}(-\mathrm{kt})$ & Chrawal and Singh (1977), [32] \\
Logarithmic (1995) & $\mathrm{MR}=\mathrm{a}_{0}+\mathrm{aexp}(-\mathrm{kt})$ & Chandra and Singh, [34] \\
Logistic (1995) & $\mathrm{MR}=\mathrm{a}_{0} /(1+\mathrm{eexp}(\mathrm{kt}))$ & Chandra and Singh, [34] \\
Two-term exponential & $\mathrm{MR}=\mathrm{a}_{1} \exp \left(-\mathrm{k}_{1} \mathrm{t}\right)+\mathrm{a}_{2} \exp \left(-\mathrm{k}_{2} \mathrm{t}\right)$ & Henderson (1974), [35] \\
Linear & $\mathrm{MR}=\mathrm{at}+\mathrm{b}$ & Chandra and Singh (1995), [34] \\
Wang and Singh & $\mathrm{MR}=1+\mathrm{a}_{1} \mathrm{t}+\mathrm{a}_{2} \mathrm{t}^{2}$ & Wang and Singh (1978), [36] \\
Midilli & $\mathrm{MR}=\mathrm{aexp}\left(-\mathrm{kt} \mathrm{n}^{\mathrm{n}}\right)+\mathrm{bt}$ & Midilli et al. (2002), [37] \\
Diffusion approach & $\mathrm{MR}=\mathrm{aexp}(-\mathrm{kt})+(1-\mathrm{a}) \exp (-\mathrm{kbt})$ & Kassem (1998), [38] \\
\hline
\end{tabular}

For all models, the model equation coefficients, the Mse and $\mathrm{R}$ values, as well as the regression line were evaluated. The Midilli thin-layer model has the best matching (lowest error, highest regression coefficient) compared to other models (Figure 1). 

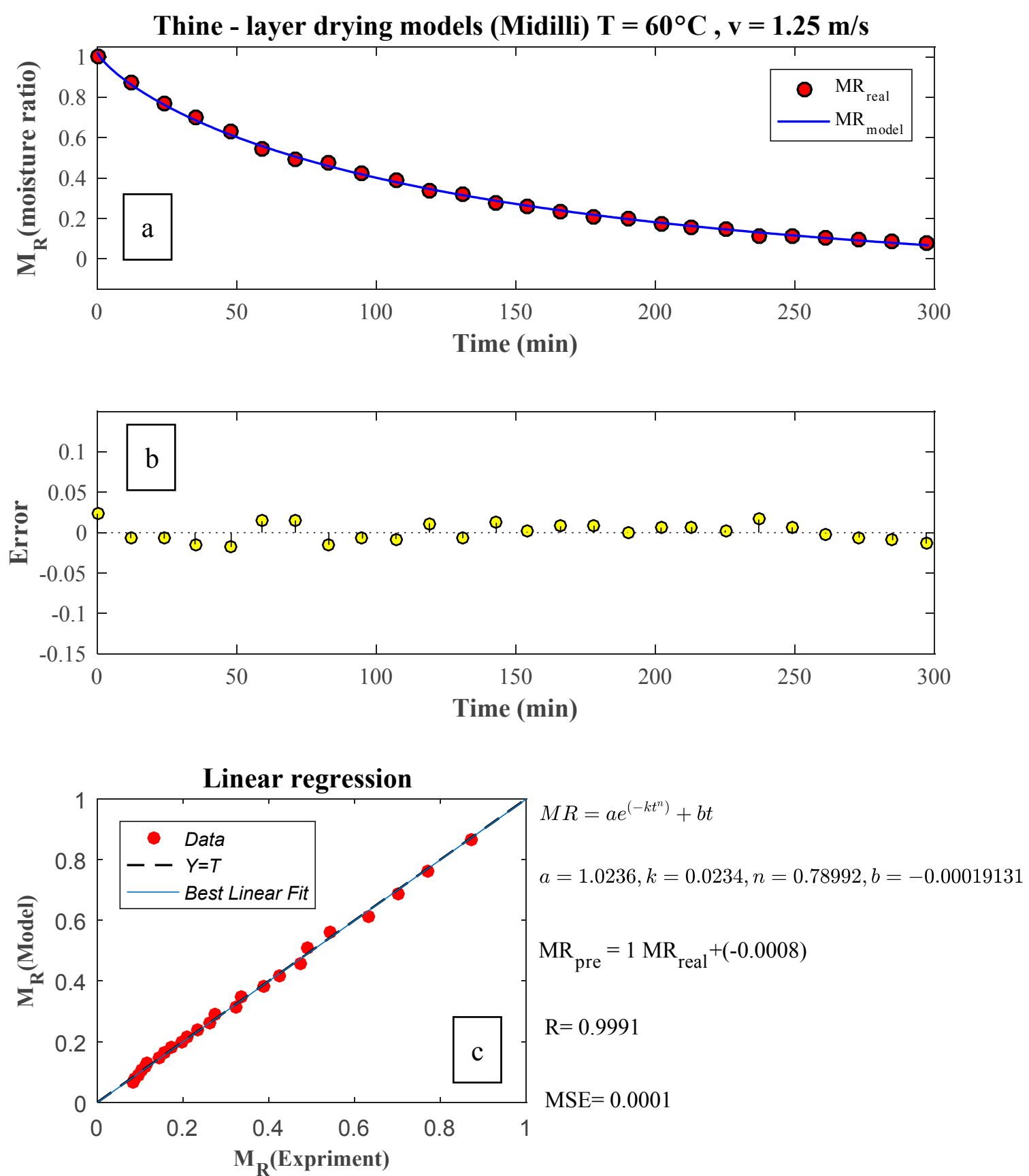

Figure 1. Midili thin layer model for the first experiment (air temperature $60{ }^{\circ} \mathrm{C}$ and speed $1.25 \mathrm{~m} / \mathrm{s}$ ); the constant amounts of the thin layer model are shown in the figure. Also, the correlation coefficient, regression line, and sum of squared errors are also provided for the proposed model. (a) values of $M_{R}$ and (b) error with respect to time, and (c) comparison of $M_{R}$ values associated with the model and experiment.

\section{Comparison of the Accuracy Associated with Different Models of Thin-Layer Drying} and 3.

The comparison of the correlation coefficient $\left(\mathrm{R}^{2}\right)$ for ten thin-layer models is shown in Figures 2 


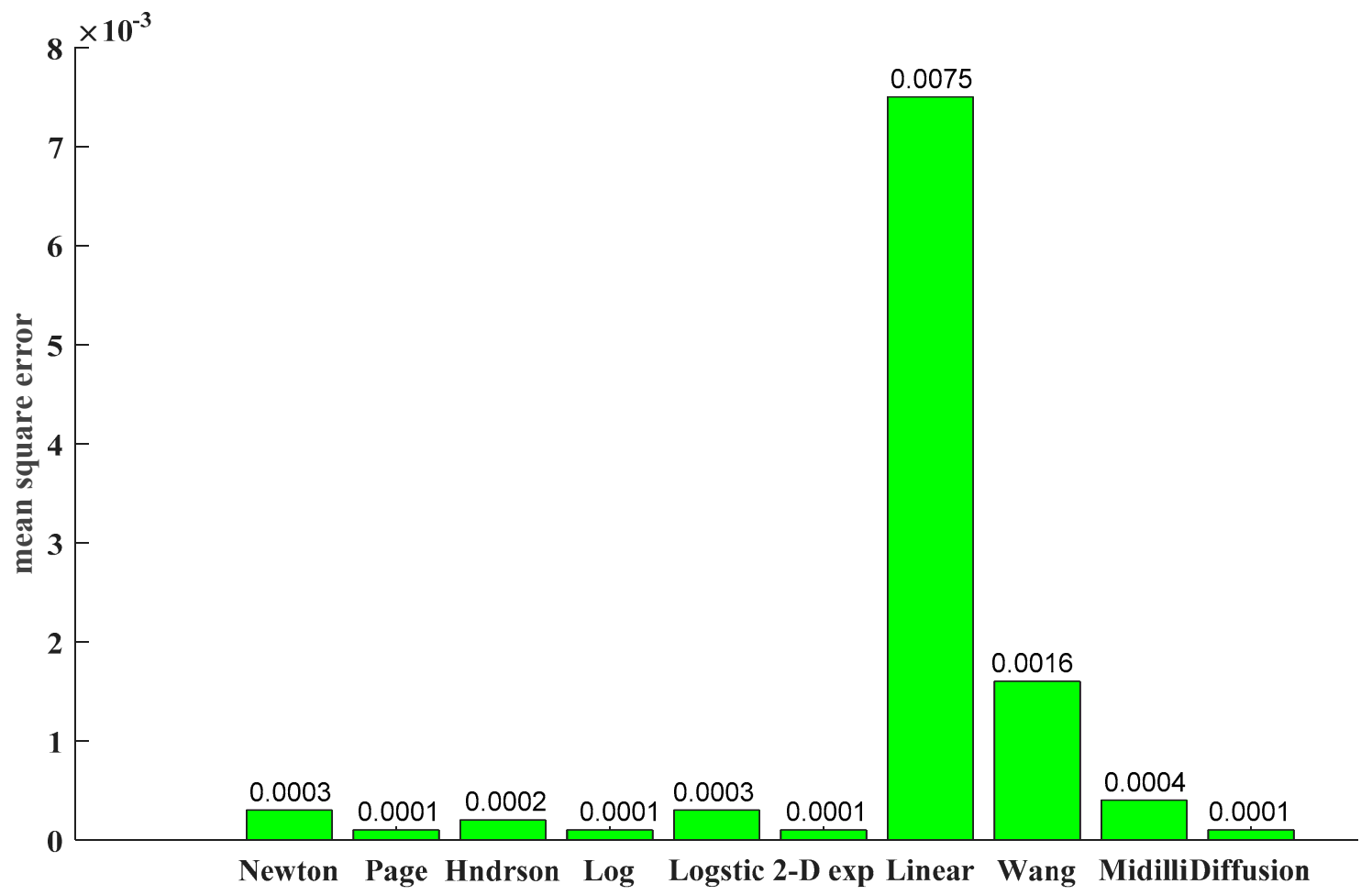

Figure 2. Comparison of the sum-of-squared-errors for ten thin-layer models.

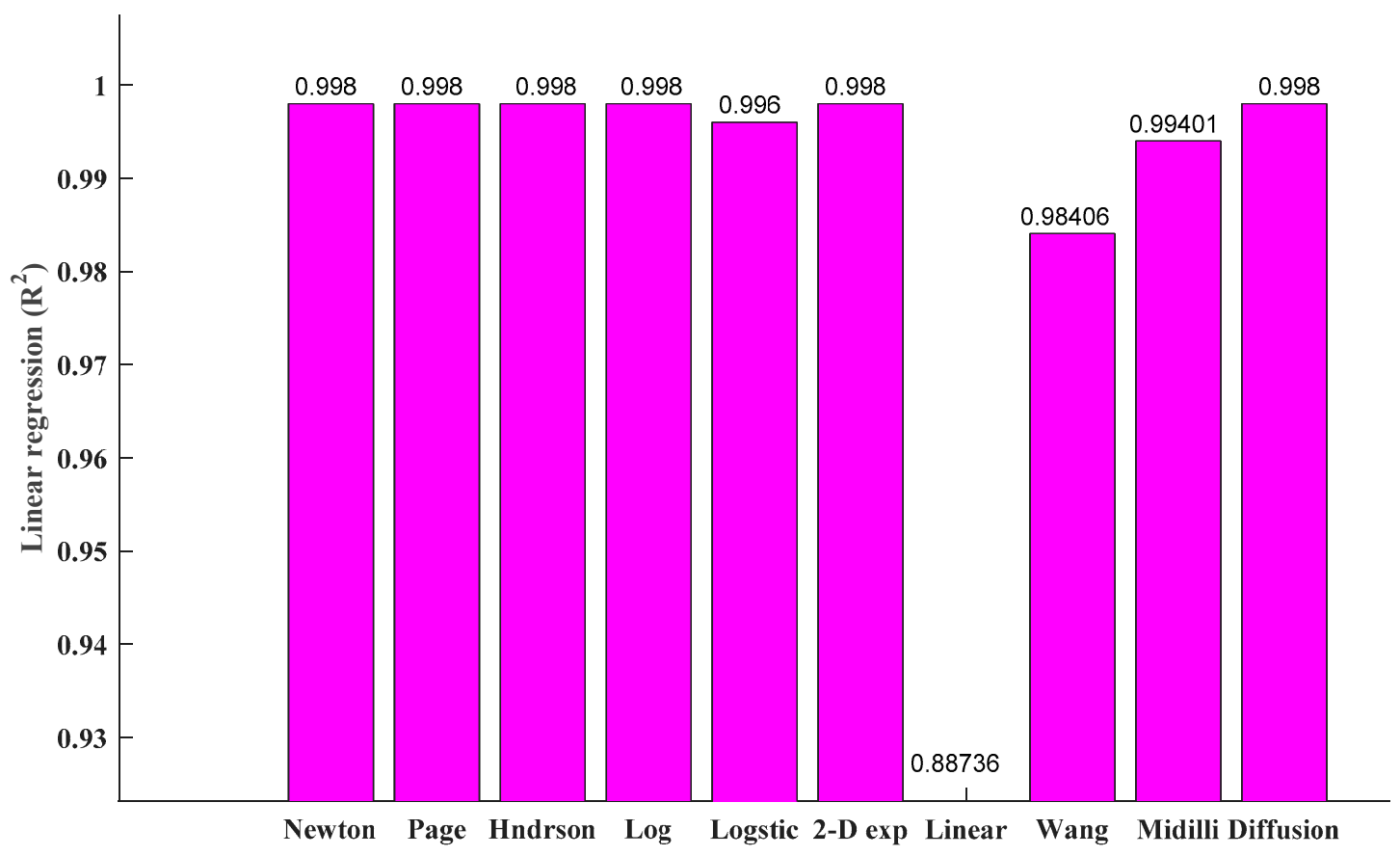

Figure 3. Correlation coefficient $\left(\mathrm{R}^{2}\right)$ for ten thin-layer models.

For the Midili model, the coefficients of the thin-layer equation for all experiments are presented in Table 2. 
Table 2. Implementing the Midili model for all data.

\begin{tabular}{ccccccc}
\hline & \multicolumn{7}{c}{ Midili } \\
\hline Run No & Temp@ & V (m/s) & A & K & n & B \\
\hline Run 1 & 60 & 1.25 & 1.002705 & 0.015509 & 0.885033 & $-4.11 \times 10^{-5}$ \\
RUN 2 & 55 & 1.25 & 1.036377 & 0.034653 & 0.649945 & -0.00046 \\
RUN 3 & 50 & 1.25 & 1.020234 & 0.020321 & 0.729967 & $1.41 \times 10^{-5}$ \\
RUN 4 & 60 & 0.75 & 1.012155 & 0.016581 & 0.805009 & -0.00024 \\
RUN 5 & 55 & 0.75 & 1.005385 & 0.014143 & 0.784523 & -0.00025 \\
RUN 6 & 50 & 0.75 & 1.024748 & 0.02253 & 0.621478 & -0.00021 \\
\hline
\end{tabular}

As shown in Table 2, for the Page model at a specific air velocity with decreasing air temperature, the coefficient $\mathrm{K}$ increases at first, then decreases. Also, power $n$ reduces then increases. Also, at a constant temperature, with decreasing air velocity, $\mathrm{K}$ increases and power $n$ decreases.

\section{Neural Network Modeling}

There are recently growing interests in multi-layer networks in general $[39,40]$. To evaluate the performance of the multi-layer perceptron network, multi layers of different topologies with various neurons were used. In the first step, after learning the network, the mean squared error (MSE) of the network was calculated, and based on that, the most appropriate topology was selected. During the modeling, $60 \%$ of the data were randomly assigned as training data and the rest of them were taken as test data and validators. The setting parameters for the artificial neural network were chosen according to Table 3. The feed-forward back propagation network (FF-BP) with the LM (Levenberg-Marquardt) learning algorithm and tansig (hyperbolic tangent) as a transfer function for the hidden layer produced the least training error in comparison with other settings. In neural network modeling, mean squared error (MSE) was chosen as the objective function. By trial and error, the best topology was selected, and this topology has 9 neurons in hidden layer. That topology, for the test data, predicted the moisture content, while MSE was 0.0005 , and regression coefficients of $R=0.996$. The obtained results indicate the ability of the neural network as a tool for predicting changes in the content of moisture with the time that can be used in dry control systems [41,42]. In Table 3, the numerical values of the regulatory parameters of the neural network used in the modeling are presented. In the following, only the results of the best neural network topology are presented in the prediction of moisture content.

Table 3. Regulatory parameters of artificial neural network.

\begin{tabular}{lc}
\hline$R=\sqrt{\frac{\sum_{l}^{n}\left(M_{R}^{\text {model }}-\overline{M_{R}^{e x p}}\right)^{2}}{\sum_{l}^{n}\left(M_{R}^{e x p}-\overline{M_{R}^{e x p}}\right)^{2}}}$ & 0.996 \\
$M S E=\frac{\sum_{l}^{n}\left(M_{R}^{\text {model }}-M_{R}^{\text {exp }}\right)^{2}}{N}$ & 0.0005 \\
Objective Function & MSE \\
Training Algorithm & LM \\
Transfer Function & tansig \\
Topology & $3-9-1$ \\
Network Type & FF-BP \\
\hline
\end{tabular}

The evaluations of the actual data matching with the data obtained from the neural network were divided into three categories: Training 60\%, validation 20\%, and testing 20\% (Figure 4). The value of the root-square errors and linear regression coefficients were calculated for each of the three groups (Figure 5). In Figure 6, the predicted values by the neural networks were evaluated with the experimental results, and in Figure 6, the values of the correlation coefficient and the mean value of the errors were evaluated. One of the major issues with artificial neural networks is that the models are quite complicated. Overfitting is one of the biggest challenges that a machine learning engineer must combat. The most popular method to do so in practical applications is the so-called early 
stopping. For the aim of utilizing stopping method, the validation set, regardless of the testing set and the training data set, is needed for determining stopping criteria associated with the optimization algorithm. The learning algorithm in the ANN ends on the condition of increasing error for validation data, even though the learning keeps the decrease as a training data set. Whenever the calculated error associated with validation data augments and calculated for training data reduces, it is regarded as overfitting. In addition, the $\mathrm{R}^{2}$ values of all three models are close to each other which proves no overfitting has occurred.

\section{Artificial Neural network Model}
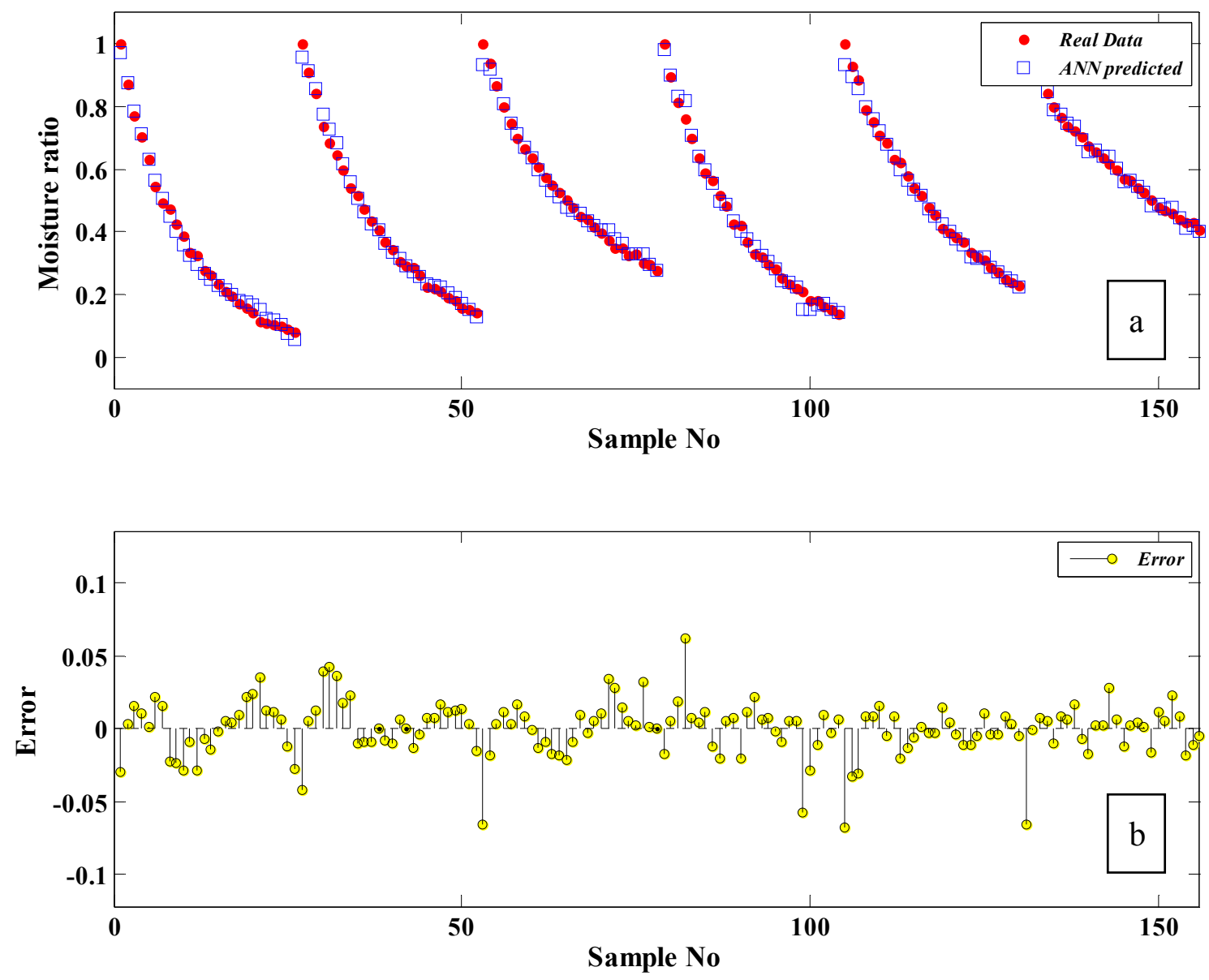

Figure 4. The actual and predicted data by the neural network for (a) moisture ratio and (b) error rate.
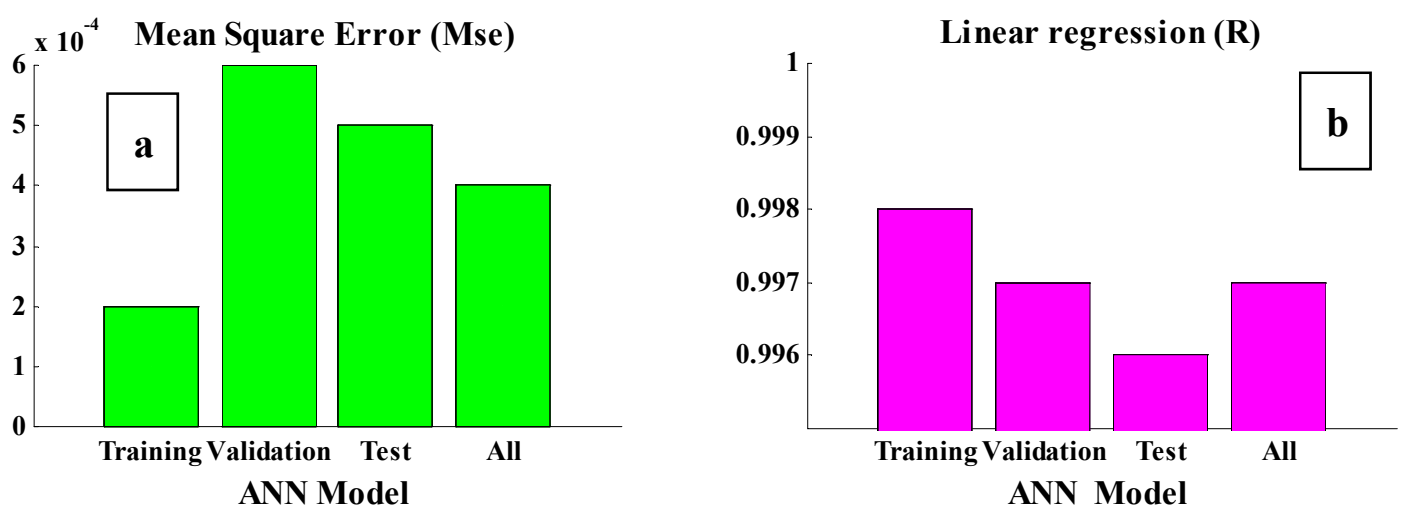

Figure 5. (a) Mean squared error (MSE) error and (b) linear regression coefficient for training data, validation and testing. 

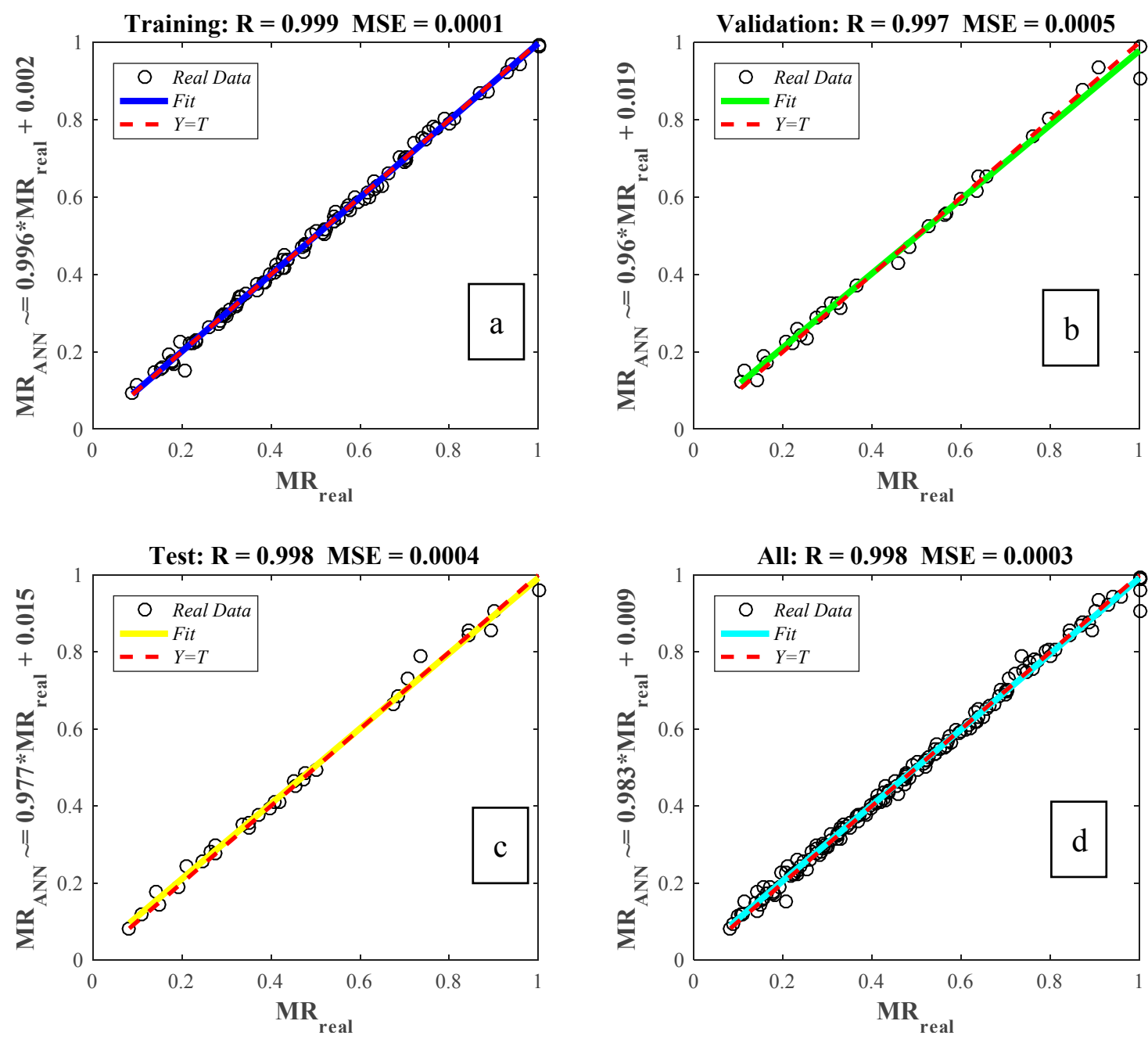

Figure 6. Neural network efficiency in (a) training, (b) validation, (c) test, and (d) prediction.

According to Figure 7, the amount of the product moisture loss in $300 \mathrm{~min}$ for three temperatures of $50{ }^{\circ} \mathrm{C}, 55{ }^{\circ} \mathrm{C}$, and $60{ }^{\circ} \mathrm{C}$ and two air velocities of 0.75 and $1.25 \mathrm{~m} / \mathrm{s}$ is depicted. Convective heat transfer and mass transfer increased with increasing the temperature difference $(\Delta \mathrm{T})$ and the convection coefficient (h). As shown in the figure above, mass transfer (the rate of moisture loss) was higher for higher air velocity, since the convection coefficient increased with rising the air velocity. Also in Figure 7 , the rate of convective heat transfer increased with increasing air temperature for a constant air velocity. The material's final quality and increasing of the total energy demand are attributed to being unfavorable effects of higher velocity. The requirement of total energy and heat transfer throughout a constant drying rate period is increased by the higher air velocity. Therefore, drying with the conditions of exceedingly high air velocity and temperature is not recommended. The drying rate and moisture content reduced sharply. According to drying curves at various temperatures, drying happens in the declining-rate period, since a consistent-rate period in the drying does not exist. It was noted that the drying process was accelerated by increasing the drying temperature, therefore lessening the drying time. 

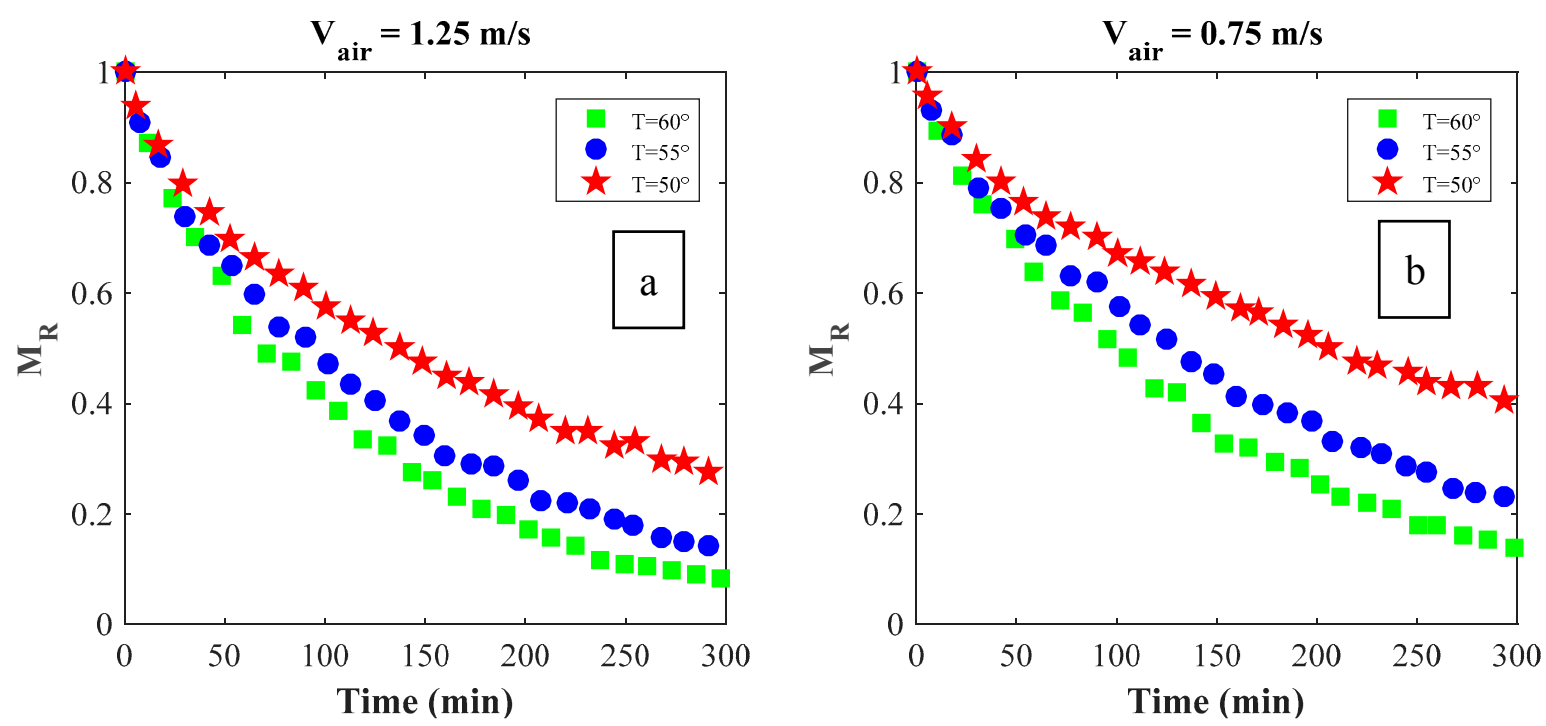

Figure 7. Moisture drop of the product in $300 \mathrm{~min}$ for three temperatures and two different air velocities (a) $\mathrm{V}_{\text {air }}=1.25 \mathrm{~m} / \mathrm{s}$ and (b) $\mathrm{V}_{\text {air }}=0.75 \mathrm{~m} / \mathrm{s}$ ).

\section{Discussions}

The moisture content of the drying product was measured by the time affected by three air temperatures, and two different velocities. According to the experimental results, at higher air velocities, the product is dried faster, due to the fact that with increasing airflow, the difference in the partial pressure of water vapor between the product and the drying air increases. As a result, the moisture transfer rate from the product to the dry air is increased, and the product is dried faster. Considering the slope of the moisture change curve, it can be understood that the drying speed is faster at the beginning of the operation (especially at higher speeds), but the drying rate is lessened by passing the time. According to the results among 10 models, the Midilli and Page thin-layer model and neural network model described the best drying behavior, which resulted in higher $\mathrm{R}$ values and lower MSEs. These models were optimized by the genetic algorithm. The air temperature is the most important factor in controlling the quality of pistachios during the drying process. As the temperature increases, the drying time and the $\mathrm{M}_{\mathrm{R}}$ decrease and the drying rate increases. The results of this analysis showed that the airflow rate has a significant effect on the drying rate of pistachios. Although the effect of airflow velocity on the drying rate is quite significant, its effect is less than air temperature. Furthermore, by referring to the experimental data and the good fit of $\mathrm{R}^{2}$ associated with each data series from semi-experimental models, it was clear that the models showed perfect agreement with the experiments, and could easily be used to predict the equilibrium moisture for each set of variables at the given temperatures. Also, the trained neural network, with $60 \%$ of the experimental data, had the ability to predict moisture at any desired temperature and velocity within the test range. To ensure this, $20 \%$ of the experimental data were considered as test data. The regression coefficient for the test data was approximately $R^{2}=0.992$, which indicates its successful performance in predicting moisture.

\section{Conclusions}

In this study, the drying behavior of a cabinet dryer was investigated at different temperatures and velocities. For the objective of explaining the drying performance of the dryer, four thin-layer drying models were implemented. When comparing those models, the superior results were achieved by the Midilli and Kucuk models and Artificial Neural Network- Genetic Algorithm (ANN-GA) model. Also, these models illustrated great conformity with experimental data pertaining to a thin layer drying process. In all conditions, the values of Root mean square error (RMSE) have been less than 0.0004 and the values of $R^{2}$ have been higher than 0.992 . It can be concluded, based on the results, 
that the proposed model properly explained the drying behavior of the cabinet dryer. Further study should be undertaken regarding other parameters affecting the proposed model, and checks on its efficiency. Moreover, the resilient consensus of switched multi-agent system must be evaluated in further investigations.

Author Contributions: This work was conducted and wrote by B.M. and M.G. under the supervision of H.M., M.H.A., and S.S.

Funding: This research received no external funding.

Conflicts of Interest: The authors declare no conflict of interest.

\section{References}

1. Rezaei, M.H.; Sadeghzadeh, M.; Alhuyi Nazari, M.; Ahmadi, M.H.; Astaraei, F.R. Applying GMDH artificial neural network in modeling $\mathrm{CO}_{2}$ emissions in four nordic countries. Int. J. Low Carbon Technol. 2018, 13, 266-271. [CrossRef]

2. Aghayari, R.; Maddah, H.; Ahmadi, M.; Yan, W.-M.; Ghasemi, N. Measurement and Artificial Neural Network Modeling of Electrical Conductivity of $\mathrm{CuO} / \mathrm{Glycerol}$ Nanofluids at Various Thermal and Concentration Conditions. Energies 2018, 11, 1190. [CrossRef]

3. Zbiciński, I.; Strumiłło, P.; Kamiński, W. Hybrid neural model of thermal drying in a fluidized bed. Comput. Chem. Eng. 1996, 20, S695-S700. [CrossRef]

4. Ahmadi, M.H.; Tatar, A.; Alhuyi Nazari, M.; Ghasempour, R.; Chamkha, A.J.; Yan, W.-M. Applicability of connectionist methods to predict thermal resistance of pulsating heat pipes with ethanol by using neural networks. Int. J. Heat Mass Transf. 2018, 126, 1079-1086. [CrossRef]

5. Maddah, H.; Aghayari, R.; Ahmadi, M.H.; Rahimzadeh, M.; Ghasemi, N. Prediction and modeling of MWCNT/Carbon (60/40)/SAE $10 \mathrm{~W}$ 40/SAE $85 \mathrm{~W} 90$ (50/50) nanofluid viscosity using artificial neural network (ANN) and self-organizing map (SOM). J. Therm. Anal. Calorim. 2018, 134, 2275-2286. [CrossRef]

6. Ahmadi, M.H.; Tatar, A.; Seifaddini, P.; Ghazvini, M.; Ghasempour, R.; Sheremet, M.A. Thermal conductivity and dynamic viscosity modeling of $\mathrm{Fe}_{2} \mathrm{O}_{3}$ /water nanofluid by applying various connectionist approaches. Numer. Heat Transf. Part A Appl. 2018, 74, 1301-1322. [CrossRef]

7. Kahani, M.; Ahmadi, M.H.; Tatar, A.; Sadeghzadeh, M. Development of multilayer perceptron artificial neural network (MLP-ANN) and least square support vector machine (LSSVM) models to predict Nusselt number and pressure drop of $\mathrm{TiO}_{2} /$ water nanofluid flows through non-straight pathways. Numer. Heat Transf. Part A Appl. 2018, 74, 1190-1206. [CrossRef]

8. Maddah, H.; Ghazvini, M.; Ahmadi, M.H. Predicting the efficiency of CuO/water nanofluid in heat pipe heat exchanger using neural network. Int. Commun. Heat Mass Transf. 2019, 104, 33-40. [CrossRef]

9. Dai, A.; Zhou, X.; Liu, X.; Liu, J.; Zhang, C. Intelligent control of a grain drying system using a GA-SVM-IMPC controller. Dry. Technol. 2018, 36, 1413-1435. [CrossRef]

10. Aghbashlo, M.; Hosseinpour, S.; Mujumdar, A.S. Application of Artificial Neural Networks (ANNs) in Drying Technology: A Comprehensive Review. Dry. Technol. 2015, 33, 1397-1462. [CrossRef]

11. Su, Y.; Zhang, M.; Mujumdar, A.S. Recent Developments in Smart Drying Technology. Dry. Technol. 2015, 33, 260-276. [CrossRef]

12. Dufour, P. Control Engineering in Drying Technology: Review and Trends. Dry. Technol. 2006, 24, 889-904. [CrossRef]

13. Freire, F.B.; Vieira, G.N.; Freire, J.T.; Mujumdar, A.S. Trends in Modeling and Sensing Approaches for Drying Control. Dry. Technol. 2014, 32, 1524-1532. [CrossRef]

14. Wu, J.; Yang, S.X.; Tian, F. An adaptive neuro-fuzzy approach to bulk tobacco flue-curing control process. Dry. Technol. 2017, 35, 465-477. [CrossRef]

15. Li, J.; Xiong, Q.; Wang, K.; Shi, X.; Liang, S. A recurrent self-evolving fuzzy neural network predictive control for microwave drying process. Dry. Technol. 2016, 34, 1434-1444. [CrossRef]

16. Lutfy, O.F.; Selamat, H.; Mohd Noor, S.B. Intelligent Modeling and Control of a Conveyor Belt Grain Dryer Using a Simplified Type 2 Neuro-Fuzzy Controller. Dry. Technol. 2015, 33, 1210-1222. [CrossRef]

17. Farkas, I. Use of Artificial Intelligence for the Modelling of Drying Processes. Dry. Technol. 2013, 31, 848-855. [CrossRef] 
18. Jumah, R.; Mujumdar, A.S. Modeling Intermittent Drying Using an Adaptive Neuro-Fuzzy Inference System. Dry. Technol. 2005, 23, 1075-1092. [CrossRef]

19. Köni, M.; Yüzgeç, U.; Türker, M.; Dinçer, H. Adaptive Neuro-Fuzzy-Based Control of Drying of Baker's Yeast in Batch Fluidized Bed. Dry. Technol. 2010, 28, 205-213. [CrossRef]

20. Vahid, M.K.; Hamed, M.M.; Etemadi, A. Determination of Effective Diffusivity Coefficient and Activation Energy of Shelled Pistachio by Using Fluidized Bed Dryer. Arch. Sid 2008, 3, 1-12.

21. Zhang, Q.; Yang, S.X.; Mittal, G.S.; Yi, S. AE-Automation and Emerging Technologies: Prediction of Performance Indices and Optimal Parameters of Rough Rice Drying using Neural Networks. Biosyst. Eng. 2002, 83, 281-290. [CrossRef]

22. Islam, M.R.; Sablani, S.S.; Mujumdar, A.S. An Artificial Neural Network Model for Prediction of Drying Rates. Dry. Technol. 2003, 21, 1867-1884. [CrossRef]

23. Erenturk, S.; Erenturk, K. Comparison of genetic algorithm and neural network approaches for the drying process of carrot. J. Food Eng. 2007, 78, 905-912. [CrossRef]

24. Zubisinsky, I.; Ciesielski, K. Extension of the Neural Networks Operating Range by the Application of Dimensionless Numbers in Prediction of Heat Transfer Coefficients. Dry. Technol. 2000, 18, 649-660. [CrossRef]

25. Mittal, G.S.; Zhang, J. Prediction of temperature and moisture content of frankfurters during thermal processing using neural network. Meat Sci. 2000, 55, 13-24. [CrossRef]

26. Broyart, B.; Trystram, G. Modelling of Heat and Mass Transfer Phenomena and Quality Changes During Continuous Biscuit Baking Using Both Deductive and Inductive (Neural Network) Modelling Principles. Food Bioprod. Process. 2003, 81, 316-326. [CrossRef]

27. Hernández-Pérez, J.A.; García-Alvarado, M.A.; Trystram, G.; Heyd, B. Neural networks for the heat and mass transfer prediction during drying of cassava and mango. Innov. Food Sci. Emerg. Technol. 2004, 5, 57-64. [CrossRef]

28. Poonnoy, P.; Tansakul, A.; Chinnan, M. Estimation of Moisture Ratio of a Mushroom Undergoing Microwave-vacuum Drying Using Artificial Neural Network and Regression Models. Chem. Prod. Process. Model 2007, 2. [CrossRef]

29. Poonnoy, P.; Tansakul, A.; Chinnan, M. Artificial Neural Network Modeling for Temperature and Moisture Content Prediction in Tomato Slices Undergoing Microwave-Vacuum Drying. J. Food Sci. 2007, 72, E042-E047. [CrossRef]

30. Cihan, A.; Kahveci, K.; Hacıhafızoğlu, O. Modelling of intermittent drying of thin layer rough rice. J. Food Eng. 2007, 79, 293-298. [CrossRef]

31. O'Callaghan, J.R.; Menzies, D.J.; Bailey, P.H. Digital simulation of agricultural drier performance. J. Agric. Eng. Res. 1971, 16, 223-244. [CrossRef]

32. Agrawal, Y.C.; Singh, R.P. Thin Layer Drying Studies for Short Grain Rice; ASAE Paper No: 3531; ASAE: St. Joseph, MI, USA, 1977.

33. Manjeet, S.; Chhinnan, M.S. Evaluation of Selected Mathematical Models for Describing Thin-Layer Drying of In-Shell Pecans. Trans. ASAE 1984, 27, 610-615. [CrossRef]

34. Chandra, P.K.; Singh, R.P. Applied Numerical Methods for Food and Agricultural Engineers; CRC Press: Boca Raton, FL, USA, 1995.

35. Henderson, S.M. Progress in Developing the Thin Layer Drying Equation. Trans. ASAE 1974, 17, 1167-1168. [CrossRef]

36. Wang, C.Y.; Singh, R.P. A single layer drying equation for rough rice. Am. Soc. Agric. Eng. 2016, 4, 115-124.

37. Midilli, A.; Kucuk, H.; Yapar, Z. A New Model for Single-Layer Drying. Dry. Technol. 2002, 20, $1503-1513$. [CrossRef]

38. Kassem, A.S. Comparative studies on thin layer drying models for wheat. In Proceedings of the 13th International Congress on Agricultural Engineering, Rabat, Morocco, 2-6 February 1998.

39. Shang, Y. Deffuant model of opinion formation in one-dimensional multiplex networks. J. Phys. A Math. Theor. 2015, 48, 395101. [CrossRef]

40. Shang, Y. Limit of a nonpreferential attachment multitype network model. Int. J. Mod. Phys. B 2017, 31, 1750026. [CrossRef]

41. Shang, Y. Resilient Multiscale Coordination Control against Adversarial Nodes. Energies 2018, 11, 1844. [CrossRef] 
42. Shang, Y. Resilient consensus of switched multi-agent systems. Syst. Control Lett. 2018, 122, 12-18. [CrossRef]

(C) 2019 by the authors. Licensee MDPI, Basel, Switzerland. This article is an open access article distributed under the terms and conditions of the Creative Commons Attribution (CC BY) license (http://creativecommons.org/licenses/by/4.0/). 